\title{
Study on the Construction Planning of Forest Products Industry in Cangwu County Based on the Principles of Green Development and Circular Economy
}

\author{
Weitao Xu ${ }^{1}$, Heding Shen ${ }^{1}$, Li Ying ${ }^{1}$, Yang Zhang ${ }^{2}$, Feng Shi ${ }^{3,}$, An Mao ${ }^{4,}$ * \\ ${ }^{1}$ Planning and Design Institute of Forest Products Industry of National Forestry and Grassland Administration, Beijing, China \\ ${ }^{2}$ National Forestry and Grassland Administration, Beijing, China \\ ${ }^{3}$ China National Forest Products Industry Association, Beijing, China \\ ${ }^{4}$ College of Forestry, Shandong Agricultural University, Taian, China
}

\section{Email address:}

mjgbw_001@163.com (Weitao Xu),shd1965@sina.com (Heding Shen), eric07092@outlook.com (Li Ying),

shun1120@126.com (Yang Zhang),cnfpia001@163.com (Feng Shi), dannymaoan@126.com (An Mao)

${ }^{*}$ Corresponding author

\section{To cite this article:}

Weitao Xu, Heding Shen, Li Ying, Yang Zhang, Feng Shi, An Mao. Study on the Construction Planning of Forest Products Industry in Cangwu County Based on the Principles of Green Development and Circular Economy. American Journal of Environmental Science and Engineering. Vol. 4, No. 3, 2020, pp. 36-41. doi: 10.11648/j.ajese.20200403.12

Received: August 10,2020; Accepted: August 22, 2020; Published: August 27, 2020

\begin{abstract}
Forest products industry is a green industry and a sunrise industry. As the largest green economy, it plays an important role in effectively alleviating the contradiction between supply and demand of wood, realizing the sustainable utilization of forest resources and realizing the development goal of circular economy. It has played a positive role in improving the ecological environment, promoting industrial agglomeration, promoting the development of related industries, and maintaining wood safety. Through scientific and technological innovation driven and industrial agglomeration, a forest products industrial cluster area integrating production and manufacturing, scientific and technological research and development, exhibition and sales will be built in Cangwu county. To strengthen and expand forest industry in Guangxi province, the level of resource utilization has been significantly enhanced, the product quality has been greatly improved, and the industrial chain has been further extended. Efforts should be made to develop the downstream furniture, wooden door, and wood flooring manufacturing industry, and also to improve the industrial scale, standardization and intensification, to strengthen the industrial innovation system, to establish the industrial chain led by leading enterprises, to create a tree shaped industrial structure, as well as to establish coordinated development. We should exhibit the modern industrial system, build the forest industry into the pillar industry of Cangwu County, turn the green water and green mountains into gold and silver mountains, and build the concentration area into the national forestry industry demonstration park in China.
\end{abstract}

Keywords: Construction Planning, Forest Products Industry, Green Development, Circular Economy

\section{Introduction}

Forest products industry is a green industry and a sunrise industry. As the largest green economy, it plays an important role in effectively alleviating the contradiction between supply and demand of wood, realizing the sustainable utilization of forest resources and realizing the development goal of circular economy. It has played a positive role in improving the ecological environment, promoting industrial agglomeration, promoting the development of related industries, and maintaining wood safety $[1,2]$. It is of great significance to absorb rural surplus labor, increase people's income, promote the prosperity and development of regional economy, and achieve the goal of targeted poverty alleviation. China's forestry industry has become one of the manufacturing industries with rapid development and good prospects [3]. Its growth rate is higher than the average rate of the whole manufacturing industry, and has become the main component of China's economic industry [4]. 
Under the background of China's vigorously promoting the supply side structural reform, industrial structure adjustment and layout reconstruction, Guangxi proposes to create a trillion level green forest industry. Cangwu county's existing industrial foundation has the conditions to further extend the industrial chain, promote the agglomeration development, and further enhance the contribution to regional economic development, so the development demand is urgent. In this paper, the construction planning of forest products industry in Cangwu county is preliminarily studied in order to better promote the development of forest industry in Cangwu county of Guangxi [5-7].

\section{Analysis of Research Status}

\subsection{Regional Location}

Cangwu county belongs to Wuzhou City of Guangxi Zhuang Autonomous Region. It is located in the east of
Guangxi, on the North Bank of the confluence of Xun River and Guangxi river. It is adjacent to Fengkai county of Zhaoqing City, Guangdong province. It is the county closest to Guangdong, Hong Kong and Macao. It is located in the intersection area of Beibu Gulf Economic Zone, Pearl River Delta economic zone and Xijiang river flow region. Wangfu town is located in the south of Cangwu County, 12 kilometers away from Wuzhou City, with convenient transportation. Wangfu industrial town is located in the north central part of Wangfu town. It is adjacent to Wuxin Expressway in the west, Wuzhou Industrial Park and dalikou Wharf in the south, Wuxin expressway entrance and Cangwu main urban area in the north. Cangwu county forest products (furniture manufacturing) industrial concentration area is located in Wangfu industrial town of Wangfu Town, Cangwu County, Wuzhou, Guangxi, with a planning area of 332.31 hectares.

Table 1. Statistics of land use status.

\begin{tabular}{llll}
\hline No. & Land use & Area $\left(\mathbf{h} / \mathbf{m}^{\mathbf{2}}\right)$ & Proportion of planned construction land $\mathbf{( \% )}$ \\
\hline 1 & Forest land & 268.95 & $80.93 \%$ \\
2 & Unused land & 12.78 & $3.85 \%$ \\
3 & Village construction land & 5.30 & $1.59 \%$ \\
4 & Waters & 13.60 & $4.09 \%$ \\
5 & Paddy field & 28.34 & $8.53 \%$ \\
6 & Fruit-bearing forest & 3.34 & $1.01 \%$ \\
7 & Total & 332.31 & $100.00 \%$ \\
\hline
\end{tabular}

\subsection{Land Use Analysis}

The scope of industrial concentration zone is from the fourth to the middle road of the district in the East, Weiyi road in the south, the new 207 National Road in the west, and the North First Road in the north. The town road runs through the land of the concentration area from the south to the north. The Xunyang river passes through the west side of the town road from the south to the north, with a planning area of 332.31 hectares. The specific land use classification and statistic are shown in Table 1.

\subsection{Enterprise Distribution}

There are 6 enterprises in the industrial concentration zone, including wood products, wooden doors, woodworking machinery, environmental protection equipment, etc., which are mainly distributed in the south of Beier road and the east of Industrial Avenue.

\subsection{Road Traffic}

The roads in the concentration area mainly include the town road and part of the area middle road and Industrial Avenue. The town road is the main external road traffic in the concentration area. It is located in the middle of the land use of the concentration area. It extends southward to the urban area of Wuzhou City and connects Cangwu county to the north. The area middle road and Industrial Avenue are under construction. The overall road network density within the planning scope is small, which does not match with the industrial development, so it needs to be improved.

\subsection{Supporting Infrastructure}

There are infrastructure facilities in the planning area of the industrial concentration area. The service center building of the Management Committee of Wangfu industrial town, the $110 \mathrm{kV}$ substation and the sewage treatment plant of the industrial town have been constructed and located in the south of the planning area, which can ensure the future operation of the concentration area. Some enterprises are under construction in the central and eastern parts of the industrial concentration area. The development of concentrated areas can not only promote the economic development of cities and towns, but also solve the employment problems of some urban population. At the same time, the cities and towns can also be used as the infrastructure guarantee for the concentrated areas.

\section{Planning Principles}

\subsection{Industrial Agglomeration and Coordinated Development}

Under the guidance of China's supply side structural reform, efforts should be made to improve the quality and efficiency of the supply system, actively guide enterprises to gather in concentrated areas, cultivate and strengthen leading industries, drive the development of upstream and downstream industries in the industrial chain, extend the 
industrial chain, optimize the industrial structure, and follow the law of industrial ladder extension, develop supporting service industry, promote the co construction and sharing of infrastructure, and pull the green The economic growth of Wuxian county and its concentrated areas should give full play to the radiation, driving function and scale benefit of the concentrated areas [8].

The development of forest products industry in the concentration area should be closely coordinated with the development of Cangwu County, combined with the development planning of Wangfu Town, so as to promote the integration of industrial development and county and town development, so as to form a benign interactive pattern in which the industrial development and the development of counties and towns rely on each other and promote each other, so that the industrial development and urban construction are integrated together, so as to achieve the vitality among industry, city and people We should strive for sustainable and coordinated development [5].

\subsection{Reasonable Layout and Phased Implementation}

Based on the analysis of the current situation of forest products industry and supply and demand in Cangwu County, combined with the construction conditions and land use status of the concentration area, the reasonable layout in time and space order was made according to local conditions. According to the principles of project concentration, industrial agglomeration, land intensive and function integration, the layout of the centralized area should be based on the planning and development sequence of forest products industry, and the industrial logistics should be considered comprehensively, so as to reduce the transportation cost. In the planning, not only the long-term objectives of the planning are considered, but also the actual development conditions are considered. Under the condition of meeting the long-term objectives, the operability of the short-term objectives should be increased as much as possible.

\subsection{Resource Saving and Land Intensive}

According to the industrial orientation and development goals of the concentration zone, high requirements for admission standards are formulated, land conservation and project cluster development are strengthened, resource allocation is optimized, and the quality of industrial development is improved. Enterprises adopting modern ecological technology, energy-saving technology, water-saving technology, recycling technology and information technology are encouraged to enter the park In order to improve the efficiency of resource utilization, low-end, high energy consumption and high pollution enterprises are prohibited.

In accordance with the general requirements of strictly controlling the increment, invigorating the stock, optimizing the structure and improving the efficiency, the management of land use in the concentrated areas should be strengthened with the theme of saving, efficient, scientific and reasonable land use [5]. The intensive and economical land use should be vigorously promoted to form industrial clusters, and the industrial upgrading should be orderly guided. The utilization rate of industrial land and the input-output ratio per unit area should be increased to the maximum extent, so as to promote healthy and sustainable development.

\subsection{Innovation Driven, Improving Quality and Efficiency}

Taking innovation driven and independent innovation as an important support for sustainable development of the concentration areas, we should improve the innovation system, broaden the new development model, cultivate new driving forces for development, realize the transformation from factor driven and investment driven to innovation driven, and promote the innovative development of forest products industry. Strengthen the deep integration of guiding innovation chain with industrial chain, entrepreneurial chain and information chain, focus on introducing leading backbone enterprises with core technology, and vigorously develop headquarters economy; actively guide and encourage enterprises entering the park to carry out thinking innovation, mode innovation, technological innovation, etc., strengthen the dominant position of enterprises in technological innovation, and speed up the original innovation, integrated innovation and introduction, digestion and absorption We should also innovate the management and business environment of the concentration area, improve the infrastructure and functional support, and accelerate the upgrading of the concentration area.

Adhere to scientific development, put the improvement of development quality and efficiency in a more prominent position, adhere to structural adjustment, eliminate backward production capacity, optimize industrial layout, expand product varieties, improve product quality and enhance core competitiveness. Actively guide enterprises to adopt international standards and establish quality certification and environmental certification system.

\subsection{Green Development, Circular Economy}

The planning is based on the sustainable utilization of wood resources, follows the principles of green development and circular economy, adheres to the innovative development mode of "four in one" of urban and rural construction, industrial development, environmental protection and ecological priority, takes human demand as the core, strengthens resource conservation and recycling, and ensures that the ecological environment is not damaged. We will further promote the green, circular and low-carbon development mode, adhere to the new industrialization road with high scientific and technological content, low resource consumption, less environmental pollution and good economic benefits, improve the recycling utilization rate of resources and the added value of products, and promote the establishment of a green, low-carbon and circular development industrial system, so as to achieve the best balance of ecological, economic and social benefits. 


\section{General Layout Plan}

\subsection{Planning Concept}

Through the development of industrial chain, we should give full play to the effect of industrial chain, industrial cluster, and industrial chain. Through the linkage development with the radiation area, good industrial interaction will be formed in Cangwu county to promote the transformation and upgrading of forest industry in Cangwu county.

With the forest products industry chain as the link, the concentration area actively guides enterprises to gather in the concentration area, cultivates and strengthens the leading industry, drives the development of the upstream and downstream industries of the industrial chain, promotes the economic growth of the concentration area, and follows the law of industrial gradient extension to develop the supporting service industry [9]. According to the principles of project centralization, industrial agglomeration, land intensive and function integration, the functional blocks and road network of the concentrated area will be planned and positioned. Combined with the concept and characteristics of urban development, the largest panel furniture base in Southeast Guangxi will be built with furniture industry as the main body, so as to realize the integration of urban and rural development and the integration of industry and city development.

The main function of the concentration area is to serve as the gathering area and demonstration base of forest products industry, integrating production and manufacturing, scientific and technological research and development, exhibition, trade circulation, comprehensive services, etc., and gradually cultivate and form an industrial cluster with furniture industry as the main body. According to the main functional characteristics of the concentration area and the condition characteristics of the planned land, the layout mode of "one center, two axes and six districts" is proposed, which is composed of six regions: the starting development area, the production area of basic materials, the production area of furniture products, the development area of supporting industries, the trade exhibition area and the residential area.

\subsection{Planning Concept}

The planning layout is a spatial structure of "one center, two axes and six districts". One heart: the trade exhibition center of the concentration area, which integrates the functions of product trading, furniture display, customer reception, image display, etc., is also a window to display the image of the industrial concentration area. Combining with the modern industrial landscape of the concentration area and the planning concept of green environmental protection, the comprehensive landscape of the trade exhibition center is vigorously built. Two axes: the North-South Town Road and the East-West middle district road are the main transportation links and industrial development axes. Town avenue runs through the whole concentration area from north to south, which is an important external transportation link and vertical industry development axis. The central road of the area runs through the land of the concentration area from east to west, forming the landscape green belt and horizontal industrial development axis. Six areas: start-up development area, basic material production area, furniture production area, supporting industry development area, trade exhibition area, residential area.

\subsection{Function Partition}

According to the industrial construction content and functional requirements, as well as the land use nature, external traffic conditions, road network layout, existing enterprise distribution and industrial situation, land leveling status and next step planning and other factors, the concentration is divided into six areas: starting development area, basic material production area, furniture production area, supporting industry development area, trade exhibition area and residential area Domain. Among them, the first stage development area, basic material production area, trade exhibition area and residential area, the second stage development of furniture products production area and supporting industry development area. The division of functional areas should strive for reasonable production process, simple and clear boundary, smooth connection, centralized and compact land use, easy implementation by stages and easy management.

\section{Comprehensive Benefit Evaluation}

\subsection{Economic Benefit Evaluation}

After the completion of Cangwu county forest products (furniture manufacturing) industrial concentration zone, through the collaborative promotion of plywood, fiberboard, particleboard, sawn timber, finger jointed timber, furniture, wooden door, wooden floor and other industries, the forest products industry development will be promoted. By 2021, the output value of the concentrated area will exceed 4.144 billion yuan, the profit will be about 414 million yuan, and the tax revenue will be about 249 million yuan. By 2025, the output value of the concentrated area will reach 10.424 billion yuan, the profit will be about 1.267 billion yuan, and the tax revenue will be about 760 million yuan. Through the industrial development planning of the concentration area, promote the development of forest products industry, and drive the output value of related industries to exceed 10 billion yuan. By 2025, the output value of forest products industry in Cangwu county will exceed 20 billion yuan.

\subsection{Social Benefit Evaluation}

The forest products (furniture manufacturing) industrial concentration area in Cangwu county will be built into a forest product industrial base with scale benefits, including the starting development area, the production area of basic materials, the production area of furniture products, the development area of supporting industries and the trade 
exhibition area. The construction of the forest products industry cluster area will bring huge industrial agglomeration effect in Cangwu county and its surrounding areas, and play a good radiation and pulling action It can effectively promote the construction and development of forest industry system in Cangwu County, meet people's growing ecological demand and ecological consumption demand, and comprehensively adjust and improve the industrial structure of Cangwu county's economic construction [10].

As an industry of enriching the people, the forestry industry can fully transform the resource advantage into the economic advantage, make the green water and green mountains become the golden mountain and silver mountain, drive the employment and income increase of the local people, and effectively promote the development of Finance and insurance, foreign trade, information consultation, transportation, chemical industry, packaging, service and other industries. It has ten advantages for expanding domestic demand and promoting the prosperity and development of local economy important [11].

The construction of the concentration area will greatly stimulate the enthusiasm of local farmers for afforestation. Through afforestation and sales of timber, timber transportation and timber primary processing, forest farmers can obtain considerable income, drive farmers to get rid of poverty and become rich, give full play to the important position of forestry industry in precision poverty alleviation, and contribute to the local goal of poverty alleviation.

The development of forest products industry in Cangwu county can provide about 14000 direct employment opportunities and provide a large number of indirect jobs. According to relevant research and calculation, the industry can drive the employment ratio of relevant industries to $1: 1$, so the number of employment increases by about 28000 . In order to increase local employment, transfer local rural surplus labor force and attract people to go out. It is of great significance for migrant workers to return home and return talents. While solving the problems of social stability and left behind children, it can stimulate the consumption of local housing, catering and entertainment, and make due contributions to the overall development of Cangwu county.

\subsection{Environmental Benefit Evaluation}

Forestry is the main body of ecological construction and protection, and the main position of building ecological civilization and realizing the harmony between man and nature. Vigorously developing the forestry industry is conducive to promoting the construction of ecological civilization, breaking through the constraints of resources and environment, and sharing the fruits of green development. It is of great significance to promote the "innovation, coordination, green, open and sharing" development of forestry. As an important part of forestry industry, forest industry is called green industry, which has great ecological benefits.

Through the rational utilization of wood resources, the concentration area can maximize the value-added of wood and reduce the formation of waste. While saving resources and reducing waste, it can effectively alleviate the shortage of wood resources in China. It is of great significance to protect natural forest resources, protect ecological environment and alleviate environmental pollution.

Wood has a significant role in carbon sequestration. Through the comprehensive and reasonable utilization of wood in the concentration area, the utilization rate of wood is improved, and the carbon stored in the wood can be saved to the maximum extent, which is of great significance to reduce carbon dioxide emission and protect the ecological environment; the centralized heating mode can effectively reduce the emission of pollutants, which is conducive to the maintenance of China's health It is of great significance to achieve the goal of energy conservation and emission reduction of the State Council by 2020 .

\section{Conclusion}

Cangwu county forest products (furniture manufacturing) industrial concentration area has good economic, social and environmental benefits. Efforts should be made to develop the downstream furniture, wooden door, and wood flooring manufacturing industry, and also to improve the industrial scale, standardization and intensification, to strengthen the industrial innovation system, to establish the industrial chain led by leading enterprises, to create a tree shaped industrial structure, as well as to establish coordinated development. We should exhibit the modern industrial system, build the forest industry into the pillar industry of Cangwu County, turn the green water and green mountains into gold and silver mountains, and build the concentration area into the national forestry industry demonstration park in China.

\section{Author Contributions}

The Manuscript was written through contributions of all authors. All authors have given approval to the final version of the manuscript.

\section{Conflicts of Interest}

The authors declare that they have no competing interests.

\section{Acknowledgements}

The research was supported by funding from Department of Forestry and Grassland Reform and Development, State Forestry and grassland administration (Project: "Study on circular economy of forestry industry").

\section{References}

[1] Xu W. T, Shi F, Mao A, Yuan Y. F (2020) Study on Sustainable Development of Forest Products Industry Based on Circular Economy. American Journal of Agricultural and Forestry, 8 (4): 126-130. 
[2] Wang Z, Yang H, Wang D, Zhao Z (2019) Spatial distribution and growth association of regeneration in gaps of Chinese pine (Pinus tabuliformis Carr.) plantation in northern China. Forest Ecology Management, 432: 387-399.

[3] Wang Z, Yang H, Dong B, Zhou M, Ma L, Jia Z, Duan J (2017) Effects of canopy gap size on growth and spatial patterns of Chinese pine (Pinus tabulaeformis) regeneration. Forest Ecology Management, 385: 46-56.

[4] Xiong M. Z, Bao F. C (2006) Study on the development superiority of modern wood industry in recycling economy. Wood Industry, 20 (1): 5-7.

[5] Zhang J (2015) Planning of forest resin board integrated industry demonstration area in Ji'an, Jiangxi Province. China Forestry Products Industry, 42 (4): 47-53.

[6] China Forest Products Industry Association, State Forestry Bureau Forest Industry Planning and Design Institute. China Wood Based Panel Industry Report 2019. 2019.
[7] Li H. B, Lin Z. F (2019) Study on forestry industry ecology based on circular economy. Jiangxi Agriculture, 12: 88-89.

[8] Cui W. Z (2019) Study on the development of forestry industry from the perspective of circular economy. Science and Technology Innovation Herald, 16 (19): 255-257.

[9] Li Z. Q, Qi J. G, Wu G. S (2008) New Basic Principles of Modern Circular Economy: From 3R to 5R. The Journal of Quantitative \& Technical Economics, 25 (1): 53-59.

[10] Ji M, Geng L. M (2019) Study on the development of forestry biomass energy based on forestry circular economy. China Forestry Economy, 5: 12-14.

[11] Zhang Z. Z (2019) Theoretical Logic of the "Material Circulation and Reutilization" Thought: Based on the dimension of Marxist Green Development. Journal of Central South University of Forestry \& Technology (Social Sciences), 13 (1): 12-17. 